\title{
Article
}

\section{The Role of Ab-Anbars in the Vernacular Architecture of Iran with Emphasis on the Performance of Wind-Catchers in Hot and Dry Climates}

\author{
Fazeleh Yousefi ${ }^{1, *}$ and Francesco Nocera ${ }^{2}(\mathbb{D}$ \\ 1 Department of Art and Architecture, University of Yazd, Yazd 89138-75639, Iran \\ 2 Department of Civil Engineering and Architecture, University of Catania, 95131 Catania, Italy; \\ fnocera@unict.it \\ * Correspondence: fazeleh.yousefi@stu.yazd.ac.ir; Tel.: +98-938-794-4468
}

check for updates

Citation: Yousefi, F.; Nocera, F. The Role of Ab-Anbars in the Vernacular Architecture of Iran with Emphasis on the Performance of Wind-Catchers in Hot and Dry Climates. Heritage 2021, 4, 3987-4000. https://doi.org/ 10.3390/heritage4040219

Academic Editor: Tor Broström

Received: 14 September 2021

Accepted: 21 October 2021

Published: 27 October 2021

Publisher's Note: MDPI stays neutral with regard to jurisdictional claims in published maps and institutional affiliations.

Copyright: (c) 2021 by the authors. Licensee MDPI, Basel, Switzerland. This article is an open access article distributed under the terms and conditions of the Creative Commons Attribution (CC BY) license (https:// creativecommons.org/licenses/by/ $4.0 /)$.

\begin{abstract}
Vernacular and traditional Iranian architecture has always acted rationally, harmoniously, and climate-friendly to meet the needs of the people in dealing with the environment. In addition, without harming the environment, they have achieved the best initiatives with the least facilities. For example, we can mention that the Ab-Anbars in arid and desert areas of Iran, which are used to store water in seasons with precipitation for use in the rest of the year, has been an optimal way to use natural resources and provide climate comfort. The Ab-Anbars are realized with ventilated cisterns through openings on their roof or wind-catchers to keep the water cool and provide comfortable conditions for the occupants. In order to study the essential role of natural ventilation and cooling in the Ab-Anbars, thermal analysis with CFD software was carried out to assess the effectiveness of a typical wind-catcher according to different wind directions in Yazd city. The results showed that AbAnbars have played an important role in reducing cooling loads and supply the necessary ventilation rate of buildings and can be used in the future for application in contemporary architecture and urban planning.
\end{abstract}

Keywords: vernacular architecture; Ab-Anbar; wind-catcher; CFD; hot and dry climate; Iran; Yazd

\section{Introduction}

As the world has been threatened by the effects of global warming, the increase in the concentration of greenhouse gases and the depletion of natural reserves have led people to consider the use of resources, and to take precautions against climate change. Thus, once again, our attention is drawn to vernacular and traditional architecture [1].

Vernacular architecture, also known as local or regional architecture, is defined as the unconscious "realization" and "embodiment" of the culture of the society with the requirements of the people in nature [1]. In the traditional housing patterns, all buildings are compatible with the climate and the geography. In addition, along with the shared culture, using similar materials and forms creates a habitual harmony and integrity between buildings [2]. Iran is a vast country with different climatic zones, and, in the past, traditional builders have presented several logical climatic solutions in order to enhance human comfort. In fact, this emphasis has been one of the most important and fundamental features of Iranian architecture. To a significant extent, Iranian architecture has been based on climate, geography, available materials, and cultural beliefs [3].

Water is the source of life, and water supply to meet daily needs has always been one of the most important concerns of the people. This issue is very important in hot and dry regions such as deserts and southern regions of Iran. The architects of the past, with their wisdom and experience, found a suitable solution to this problem and, by building Ab-Anbars, they were able to improve the living conditions in these areas. These buildings provided cool water for desert travelers and people living in that area. It is 
noteworthy that the Ab-Anbars in each region are in harmony with all the facilities and environmental and natural limitations of their bed and have been in complete harmony with their environment [4].

The issue of how and in which way the ancient and wise Iranian architecture has succeeded in fulfilling the needs (water, energy, and comfort) of inhabitants should be analyzed and studied with the aim of proposing their solution in a modern key, for application in contemporary architecture and urban planning.

Indeed, the main purpose of this study was to assess the effectiveness of a typical wind-catcher on the natural ventilation and cooling load of Ab-Anbars located in Yazd city, which are one of the masterpieces of the Iranian vernacular and traditional architecture, in hot and dry weather.

\section{Research Background}

Esmaeili et al. (2013) studied the principles of sustainable architecture in traditional and vernacular architecture of desert areas of Iran [5]. Mahan et al. (2019) pointed to the Qanat or Kariz, "Qanat is a system of water supply consisting of an underground tunnel connected to the surface by a series of shafts which uses gravity to bring water from the water table to the surface. Qanats are usually dug where there is no surface water and were originally invented by Iranians [6]." as one of the most important environmentally sustainable tools of traditional Iranian architecture for access to water [7]. Saeidian (2013) has introduced reservoirs as a sustainable water supply system in hot and dry regions of Iran and a significant element [8].

Computational fluid dynamics (CFD) has emerged as an effective tool for predicting the air ventilation and indoor and outdoor air quality improvement [9-12]. Morever, CFD simulation is a reliable method for wind-catcher studies [13]. According to Awbi (2010), CFD simulation plays a key role in the evaluation of the effectiveness of the thermal comfort of residents [14]. Indeed, Montazeri et al. (2010) evaluated the performance of a two-sided wind catcher using wind tunnel testing, smoke visualization, CFD, and analytical models and reported acceptable agreements between different methods [15]. In addition, Montazeri (2011) studied the natural ventilation of different multi-opening windcatchers, both experimentally and computationally [16]. Following the same approach, Reyes et al. (2013) studied airflow distribution, heat transfer, and thermal comfort for five different types of two-sided wind thermal performances of a wind-catcher system, incorporating evaporative cooling methods [17]. In another study, Montazeri et al. (2018) performed a detailed evaluation of the impact of the outlet openings on the ventilation performance of a single-zone-isolated building with a wind-catcher [18]. Elmualim et al. (2002) investigated and compared the performance of two wind-catchers with a square and circular cross-section [19]. Hughes and Ghani (2009) explored the capability of a four-sided wind catcher to ventilate a small classroom [20]. Jones and Kirb (2009) presented an alternative semi-empirical approach in order to provide a fast but accurate estimate of wind catcher performance [21].

Although there are many studies in the field of vernacular architecture [22] and the design of wind-catchers, as well as their ventilation performance, there is a gap in the evaluation and recognition of Ab-Anbars, which allows, thanks to the combination of wind-catcher functions and dome-roofs, the creation of a suitable comfort environment for the occupants.

\section{Ab-Anbar (Water Reservoir)}

The Ab-Anbar is a pond or indoor pool that was usually built underground to store water in cities, villages, forts, caravan routes (in ropes and caravanserais), and in the mountains. Ab-Anbars are dug to a depth of 10 to $20 \mathrm{~m}$ on the ground and is covered by a dome-like roof and equipped with several ducts. The water is collected from qanats and kept cool in the reservoir in the warm summer days. In the design of water reservoirs, the architect benefits from the change in seasonal temperature in desert regions and the isolated nature of the ground. During the winter, the water is accumulated in the reservoir, and 
in the summer, the dome-like roof of the water reservoir and the upper layer of the water grow warm. Therefore, the upper layer of water evaporates and exits from the reservoir with the air flowing in the air trap. Naturally, in order to prevent dust and insects from penetrating the reservoirs, the reservoirs are not equipped with ventilators [8]. Figure 1 shows several ancient $\mathrm{Ab}$-Anbars with multisided wind-catchers.

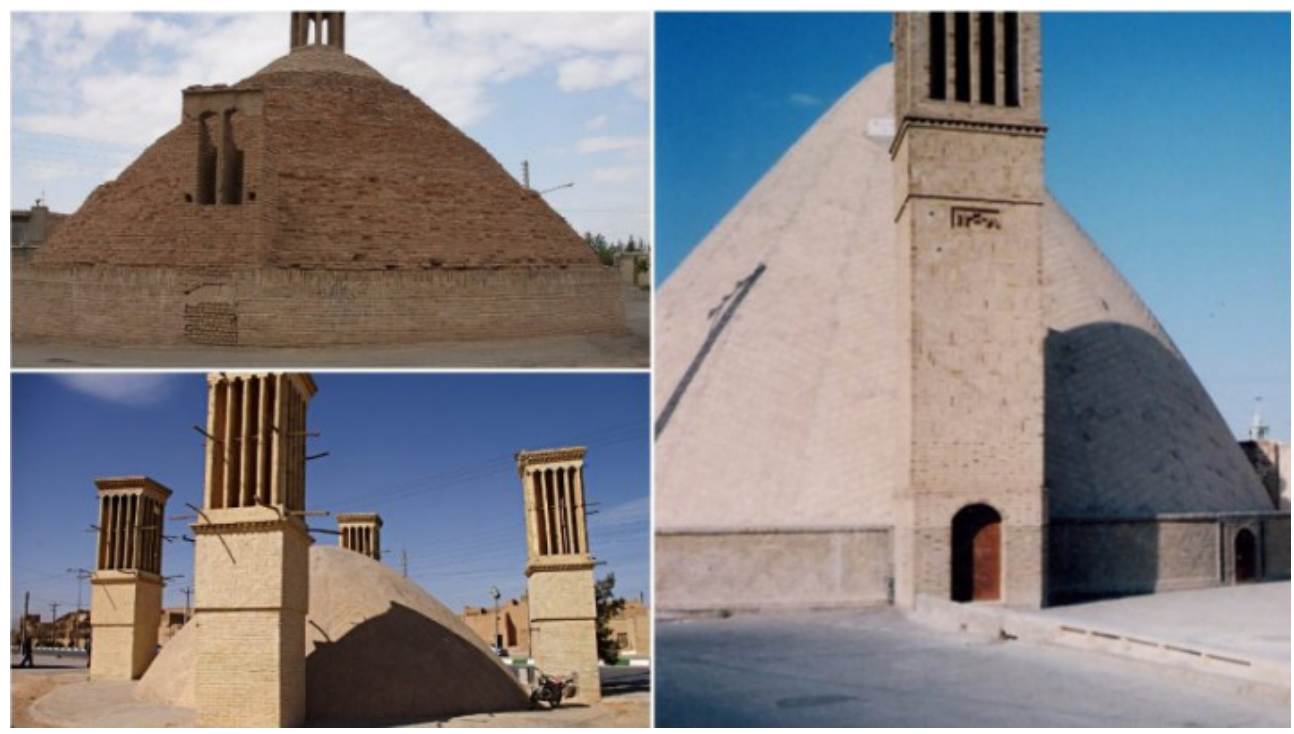

Figure 1. Several ancient Ab-Anbars with multisided wind-catchers [Source: www.thevintagenews. com/category/instant-articles/] (accessed on 3 September 2021).

Iran's oldest Ab-Anbar coincides with the emergence of the first Iranian civilizations: Ab-Anbar of the Elamite city of Duravantash in Choghaznabil (Khuzestan province), which dates back to the first half of the second millennium BC [23], and during the Achaemenid rule, there are remnants of Ab-Anbars and waterways in the area of Takht-e Jamshid. In addition, from the Sassanid era in the southern region and the islands of the Persian Gulf, there are reservoirs that are of special importance. In addition to its important role in the daily life of the people, the Ab-Anbar has a special place in the culture and beliefs of the people of this land, to the extent that it has also found a sacred aspect [24].

\subsection{Architecture of Ab-Anbar}

The construction technique and architectural style of the reservoirs have a special reputation. The architecture of these units in different regions has been influenced by local architectural styles appropriate to the climate of different regions, and builders and engineers with great care and attention to major issues such as the amount of water pressure on the floor and surface of the reservoir, ventilation, and purification and prevention of water pollution have paid full attention. In addition, another important aspect to consider here is their resistance to earthquakes. Many cities in Iran lie in a region that has been struck with massive earthquakes. However, as almost all Ab-Anbars are subterranean structures capped barely above ground level, they inherently possess stable structures [25].

In the design of $\mathrm{Ab}$-Anbars, the architects benefit from the changes in seasonal temperature in desert regions and the isolated nature of the ground. In the summer, the dome-like roof of the water reservoir and the upper layer of water becomes warm. Therefore, the upper layer of water evaporates and exits from the reservoir with the air flowing in the air trap. The Ab-Anbar can be divided into two groups:

1 - Public water reservoirs that are in villages and cities. These are individual buildings in public places.

2- Private water reservoirs that are in the houses [26]. 


\subsection{Construction}

The construction material used for Ab-Anbars was very tough and extensively used a special mortar called Sārūj made of sand, clay, egg whites, lime, goat hair, and ash in specific proportions, depending on the location and climate of the city. This mixture was thought to be completely water-impenetrable. The walls of the storage were often $2 \mathrm{~m}$ thick, and special bricks had to be used. These bricks were especially baked for Ab-Anbars and were called Ajor-e Ab-Anbari [27].

After the pit that will house the cistern has been hollowed out, the bottom is covered with slaked lime-mortar. When this floor hardens, the builder erects the tank's walls, made of baked brick or stone. The bricks are generally plunged in water before being laid. The filling between bricks or stones consists of lime-mortar. After the roofing of brick and slaked lime is laid, the tank's floor and walls are finished with a coating of plaster [28]. Plaster is an indispensable material in the construction of the Iranian cistern, as the essential function, containment of water, is achieved by the water tightness of the plaster. The type of plaster most commonly used, called saruj, is a compound from six-parts clay, four-parts lime, one-part ash, and an amount of Louie "seeds and pods of a specie of reed" sufficient to keep the compound from cracking; this last one consists of the seeds and pods of an extremely soft and pliable species of reed [29].

The spatial extent of Ab-Anbars throughout the country and the resulting climatic diversity make it possible to build a variety of Ab-Anbars with different characteristics in different places. One of these variations is the construction feature of Ab-Anbars. For example, the common method of building a reservoir in the city of Yazd has been circular and has a dome cover. In Kerman, the reservoir is quadrangular and covered with a number of arches. In addition, in Kashan, both types of construction can be seen [24]. In the following, the main elements of Ab-Anbars are introduced, which include the Reservoir, Dome, Pasheer, and Wind-Catcher (Figure 2):

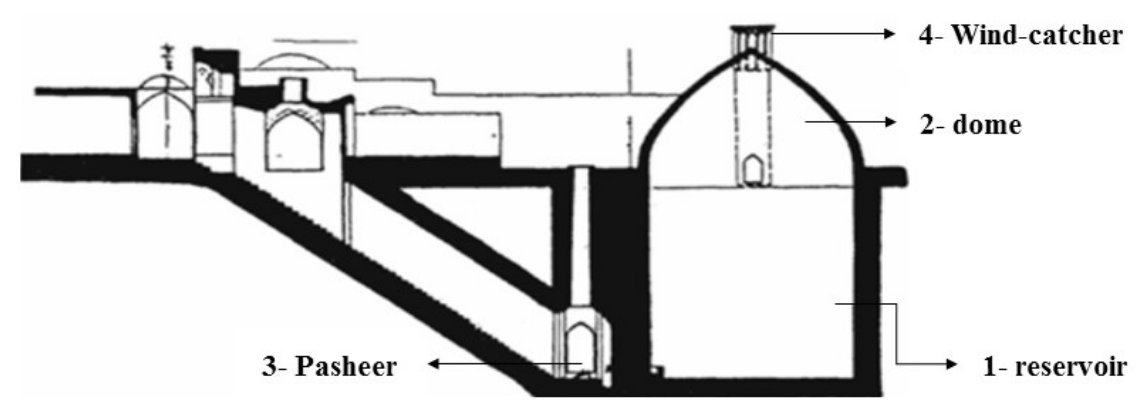

Figure 2. The main parts of an Ab-Anbar [2].

Water remains quite cool inside the reservoir as it is generally built beneath ground level and is insulated by very thick walls. In most parts of Iran, but particularly in the south, one or more ventilation towers (Badgir) are built along the edge of the cistern's roof, directly on the tank wall and connected by a duct to the upper part of the cistern chamber under the domed roof. Fresh air entering through these ducts keeps the air inside the cistern chamber circulating and the water cooled [30]. In the following, these sections are described.

\subsubsection{Reservoir (Cistern)}

The capacity of the tanks depended on the tank's form. Small tanks have a volume of 20-30 or, at most, $84-88$ cubic meters [31]. Such a volume was made in small column-less cylindrical tanks, which were dug into the ground. Big cylindrical tanks were made to a height of 10 to $20 \mathrm{~m}$. Thus, they have a capacity of between 300 to 3000 cubic meters. Regarding the width of the built tanks and the statistical factors such as the thickness of the dome, it was possible to store 3000 cubic meters of water in a $10 \mathrm{~m}$ high tank; however, 
very large tanks did not have the stability of small tanks, as were the tanks with heights more than $15 \mathrm{~m}$ [32].

\subsubsection{Dome}

One of the most important elements of an Ab-Anbar in the case of construction methods is the dome. With the traditional building methods, it was a hard job for the local masons to cover the dome diameters of more than 15 or $16 \mathrm{~m}$. The dome had the shape of a hemisphere, egg-like, of a cone. The cone-like domes had two kinds of external views: smooth-gradient and stepped [33]. Although the roofs of the cisterns were mainly built like a dome, there are other examples where the roof is built as a horizontal surface. Such roofs were built when the builders wanted to construct the building as a part of a set of functions such as mosques, schools, and Caravanserai. Usually, the cisterns were located under all other functions. The weight of the roof of such cisterns was carried by columns [34].

\subsubsection{Pasheer}

This is another part of an Ab-Anbar. It is a place that was built in the end of the stairs that led to the bottom of the tank. One or several valves were placed about one meter above the lowest point of the wall of the tank. The one-meter distance was for ensuring that the settled germs of the tank's bottom did not flow from the valve. The valves were built of brass or bronze. Of course, pasheer has been added to the structure of the water reservoirs during recent centuries. Before the installation of the iron valves, water was taken out of the reservoirs by hand and bucket. Examples of such constructions still exist. Obviously, these cisterns did not contain healthy water with today's standards. Indeed, the water poured down from the valves or the clay pots [33] was conveyed through a drain

\subsubsection{Wind-Catcher (Badgir)}

The overwhelming heat of desert areas has forced experienced architects of various buildings to think of ways to ventilate the indoor environment. One of these significant and unique methods has been the use of windbreaks in various forms. Indeed, the wind-catcher on top of Ab-Anbars allows one to avoid stagnant water and to keep it safe and drinkable.

The windcatcher system captures and conveys external air streams into the building with the aim of improving the wellbeing conditions of occupants by increasing the convective and evaporative heat transfer on body surfaces. Moreover, the air stream cools the inner surfaces of masonry and the heat stored in the Ab-Anbar building structure [35]. The geometric shapes and the inlet air stream can affect, meaningfully, the performance and use conditions of the windcatcher [36]. The design of these systems has been traditionally based on the personal experience of architects, as well as on the dignity, wealth, and social position of house owners. They can be beautiful objects or feasible architectural feature additions to buildings and are inherently durable [37,38]. Nowadays, considering geographical coordinates, wind power, and the direction of blowing wind, wind catcher designs differ in height, cross-section of the air passages, placement, and the number of openings, as well as the placement of the wind catcher with respect to the structure it cools [39]. Wind catcher systems come in various configurations to suit various building types and requirements, such as the incorporation of solar panels and light pipes to boost the stack effect $[40,41]$. A wind catcher is normally a tall structure, with heights between 5 and $33 \mathrm{~m}$, mounted over the roof of a building. Figure 3 shows several ancient wind catchers with different heights in the city of Yazd. 


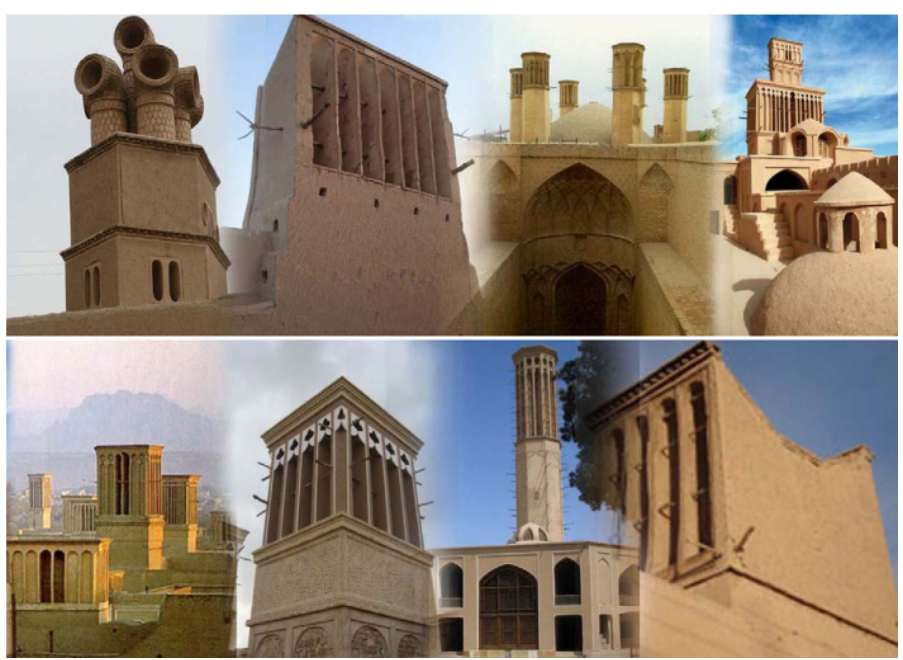

Figure 3. Several ancient wind-catchers with different configurations in the city of Yazd [15].

In desert areas of Iran such as Yazd, the sun is hot during the day and the air is cool at night, snow and rain are low and the air is dry and has low humidity. Strong winds blow and sandstorms occur a lot. In recent years, people living in these areas have taken steps to cope with this type of climate; for example, they have built houses and other buildings in specific and centralized places, digging long qanats to transfer water from mountainous areas into the city. They have also built reservoirs for people to have access to cool water in the summer. Figure 4 shows two examples of two-sided and eight-sided wind-catchers.

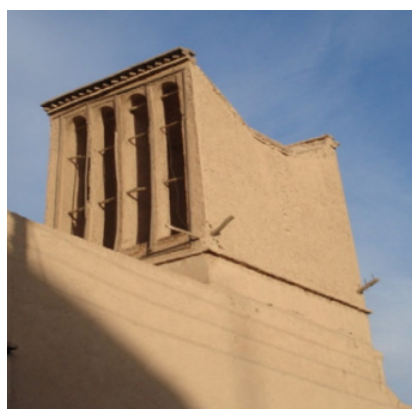

(a)

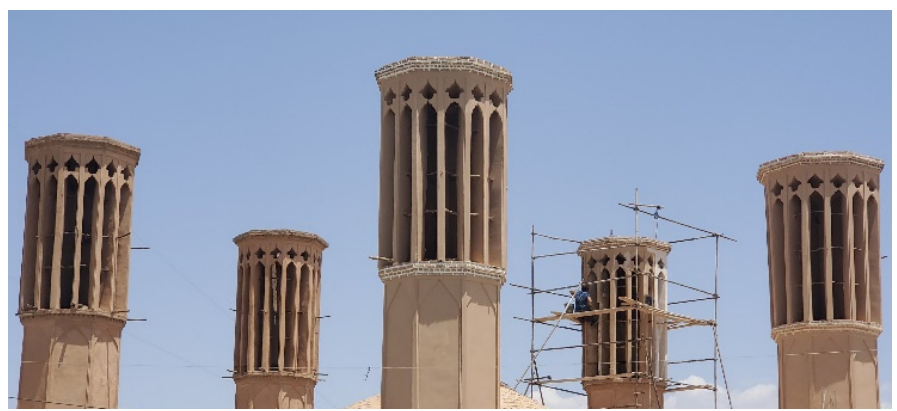

(b)

Figure 4. (a) Two-sided [15] and (b) eight-sided wind catchers (photo by authors).

When the wind blows, air enters the column through the wind-catcher vents. In the middle of this column, there is a thin wall that reduces the air pressure so that less air comes out of the other air intakes. The incoming air is then transferred into the building through a wind duct that leads to the roof of the room or hall.

\section{CFD Modeling (Computational Fluid Dynamics)}

Investigation and analysis of the Ab-Anbar were based on a numerical model and simulation of real conditions of a two-sided wind catcher connected to the Ab-Anbar space through ANSYS FLUENT 2021 (CFD), which is one of the most well-known and reliable CFD software, used in much research [19,42-44]. In a numerical model, it is crucial the knowledge of the phenomenon and the selection of the many parameters that can affect and impact the accuracy of the results. In this case, the driving forces for natural ventilation are wind and buoyancy. Differences in wind pressure along the façade and the difference between indoor and outdoor temperature create a natural airflow. The strength and direction of these forces and the resistance of the flow path determine the ventilation rate. It is challenging to control natural ventilation in order to obtain the required indoor 
air quality condition because of the complexity and difficulties in predicting ventilation rate. For this reason, a benchmarked Fluent CFD numerical model was used to solve the mass, momentum, and energy of flow conservation equations for a two-dimensional typical Ab-Anbar designed with AutoCAD.

\subsection{Simulation of Wind-Catchers and Ab-Anbar Space}

CFD modeling of two-sided wind-catchers connected to the Ab-Anbar (Reservoir) was based on a commercial CFD package FLUENT 2021. After designing a 2-D model with AutoCAD, the model geometry was implemented using hybrid mesh networks creating $527,033$ elements (Figure 5). The standard k-omega (k- $\omega)$ e turbulence model with the incorporation of modifications for Low-Reynolds-number effects, compressibility, and shear flow spreading was adopted. The standard $k-\omega$ can also be thought of as the ratio of $\varepsilon$ to $\mathrm{k}$. The overall accuracy of prediction by the standard $\mathrm{k}-\omega$ model has been proven acceptable in the simulation of building ventilation [45].
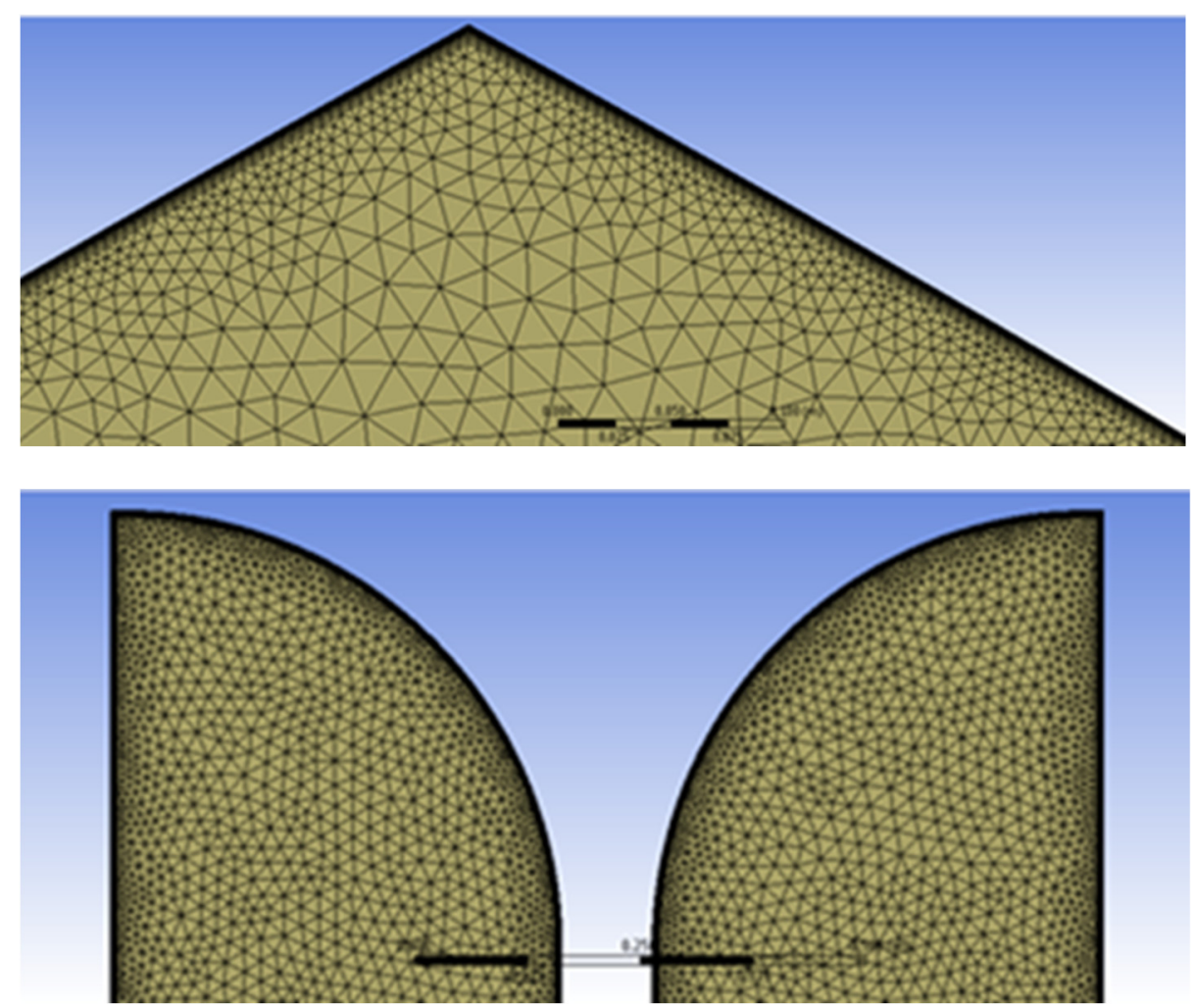

Figure 5. Triangular mesh networks [source authors].

\subsection{Boundary Conditions}

The analysis was conducted at the steady-state regime. The boundary condition at the inlet of the model domain was considered as a constant-velocity inflow boundary, while, at the outlet of the wind-catcher, it was considered as a constant pressure boundary with a pressure equal to the atmospheric pressure. In addition, a Boussinesq density model was used for the combined flow induced by wind and the buoyancy effects.

Tables 1 and 2 show thermal and physical characteristics of the typical materials and the meteorological conditions used in the buildings with wind catchers in that region, and the average monthly temperatures in Yazd for the warmest month. It is seen that the highest monthly average temperature is about $40{ }^{\circ} \mathrm{C}$ that occurs in June. The data were entered in the CFD code of calculation FLUENT for evaluating airflow and air temperature distribution in the room. 
Table 1. Meteorological conditions of the Yazd city and characteristics of the thermophysical materials.

\begin{tabular}{ccc}
\hline Material and Fluid & AIR & Brick \\
\hline Density $\left(\mathrm{kg} / \mathrm{m}^{3}\right)$ & 1.146 & 1922 \\
\hline $\begin{array}{c}\text { Cp }(\text { Specific Heat }) \\
{[\mathrm{J} /(\mathrm{kg} \mathrm{K})]}\end{array}$ & 1006 & 800 \\
\hline $\begin{array}{c}\text { Thermal Conductivity } \\
(\mathrm{W} /(\mathrm{m} \mathrm{K})\end{array}$ & 0.02662 & 0.72 \\
\hline Viscosity $[\mathrm{kg} /(\mathrm{m} \mathrm{s})]$ & $1.884 \times 10^{-5}$ & - \\
\hline Thermal Expansion Coefficient $(1 / \mathrm{K})$ & 0.003265 & - \\
\hline
\end{tabular}

Table 2. The boundary conditions for the general analysis of an Ab-Anbar in June, from Yazd.

\begin{tabular}{cccc}
\hline Condition & T (k) & V (m/s) & T-Wall (k) \\
\hline Temperature $(\mathrm{K})$ & $303 \mathrm{~K}\left(30^{\circ} \mathrm{C}\right)$ & 2.4 & $313 \mathrm{~K}\left(40^{\circ} \mathrm{C}\right)$ \\
\hline
\end{tabular}

\section{Meteorological Data}

The latest 48 year meteorological data of the weather station (located at latitude of $31^{\circ} 54^{\prime} \mathrm{N}$, longitude of $54^{\circ} 17^{\prime} \mathrm{E}$, and elevation of $1237.2 \mathrm{~m}$ ) for the city of Yazd coming from Iran's Meteorological Organization (IRIMO) were used in order to analyze the mean wind speed $(2.4 \mathrm{~m} / \mathrm{s})$ and directions of June, which is the warmest month. According to the wind rose of Yazd (Figure 6), the direction of the wind flow varies from northwest to southeast. Thus, in this study, the wind direction implemented in the model was varied in the range of $\left(-45^{\circ}\right)-\left(+75^{\circ}\right)$ with an interval of $15^{\circ}$ with the aim of evaluating the effect of the change in wind direction and velocity on the ventilation performance of two-sided wind catchers (Table 3).

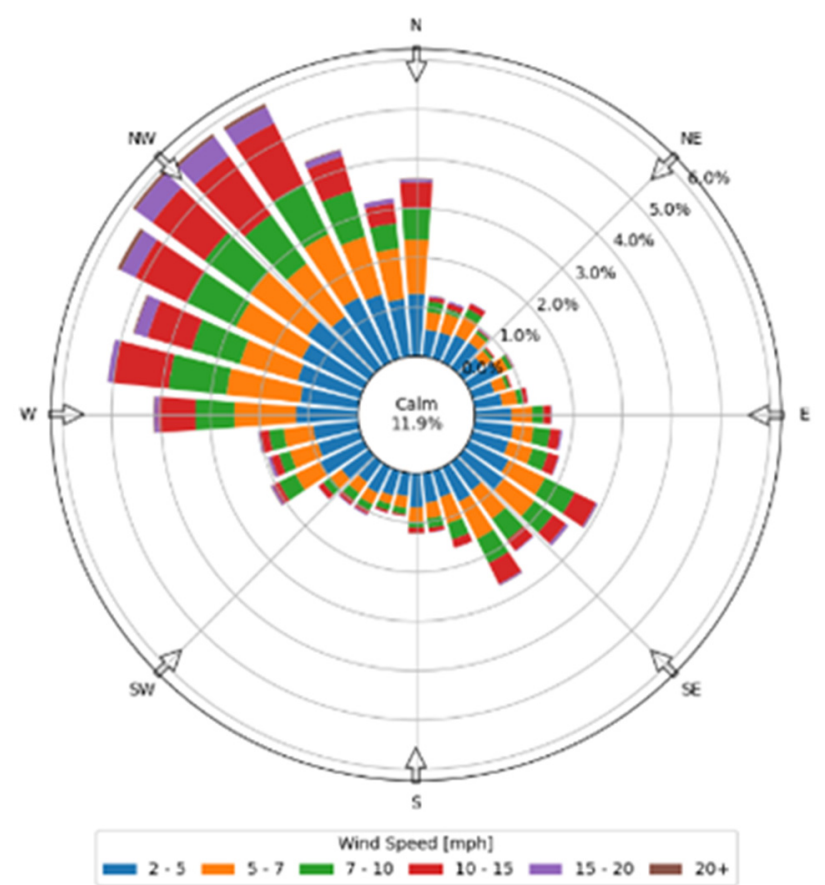

Figure 6. Wind rose of Yazd (June 1973-June 2020) [Source: www.mesonet.agron.iastate.edu] (accessed on 4 September 2021). 
Table 3. Cases.

\begin{tabular}{cc}
\hline Case No. & Wind Direction $\left(\alpha^{\circ}\right)$ \\
\hline Case A & $15^{\circ}$ \\
\hline Case B & $30^{\circ}$ \\
\hline Case C & $45^{\circ}$ \\
\hline Case D & $60^{\circ}$ \\
\hline Case E & $75^{\circ}$ \\
\hline Case F & $-15^{\circ}$ \\
\hline Case G & $-30^{\circ}$ \\
\hline Case H & $-45^{\circ}$ \\
\hline
\end{tabular}

\section{Results and Discussion}

One of the most important methods used for improving human well-being and comfort is the evaluation of ventilation [46]. Therefore, in order to evaluate the effectiveness of wind catchers and the appropriateness of comfortable airflow in the internal space, the inner temperature and velocity were analyzed

According to Figure 7, air flow enters through the inlet openings of the wind-catcher and, after rotating in the Ab-Anbar reservoir and ventilating the interior space, it exits the outlet of the wind-catcher. It should be noted that if there is water in the reservoir, the incoming air after passing through the reservoir and exchanging heat with water will have a greater impact on indoor cooling. In this study, due to the role of wind-catchers in natural ventilation, the reservoir is considered empty of water.

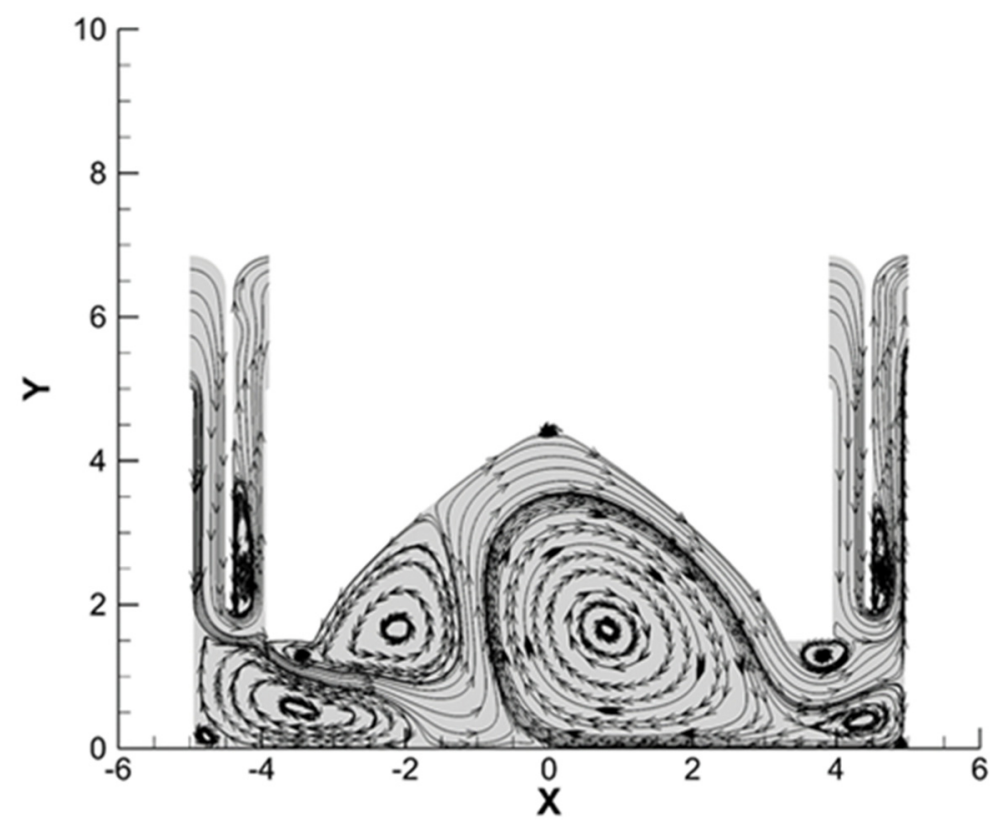

Figure 7. Pattern of air flow inside the Ab-Anbar and wind-catchers $\left(\alpha=0^{\circ}\right)$ [source authors].

As the results of the above analysis showed, wind-catchers have an effective role in natural ventilation of the space, because they help air circulation in the Ab-Anbar space and reduce the Ab-Anbar temperature in the hottest month of the year. One of the comparison factors for this case study is total temperature. As temperature is one of the main factors affecting the comfort and convenience of residents. Thermal comfort is important to humans in the space. A rough estimate of human comfort in a space is around $293 \mathrm{~K}\left(20^{\circ} \mathrm{C}\right)$ to $295 \mathrm{~K}\left(22^{\circ} \mathrm{C}\right)$. Therefore, wind-catchers make it possible for residents to live comfortably without utilizing an HVAC system "Heating, ventilation, and air conditioning (HVAC) 
system is designed to achieve the environ-mental requirements of the comfort of occupants and a process" [47]. Figure 8 shows the temperature distribution to find the best wind angle for maximum natural ventilation, which is the best contour for $\mathrm{E}$ and F. In addition, according to Table 4 , the average temperature is one of the important factors to find the best ventilation; in addition, the average temperature confirms two cases $\mathrm{A}$ and $\mathrm{F}$ as better ventilation. These two cases are +15 and $-15^{\circ}$. (It should be noted that due to the same air flow in all cases, the cooling load is the same and we do not see a significant temperature difference between the cases.) The low temperature in the main living area (under the round roof) is shown in green, which is between $304 \mathrm{~K}\left(31^{\circ} \mathrm{C}\right)$ and $310 \mathrm{~K}\left(37^{\circ} \mathrm{C}\right)$. It can also be seen that as the angle to the horizon increases, the green color decreases and the red color replaces it with more temperature, so the average temperature also increases. Furthermore, according to the data in the table, we see that with increasing wind angle, the inlet pressure decreases.

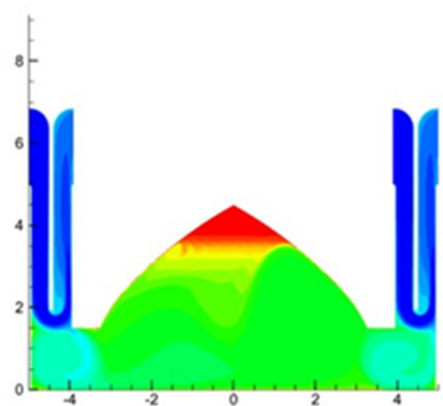

A
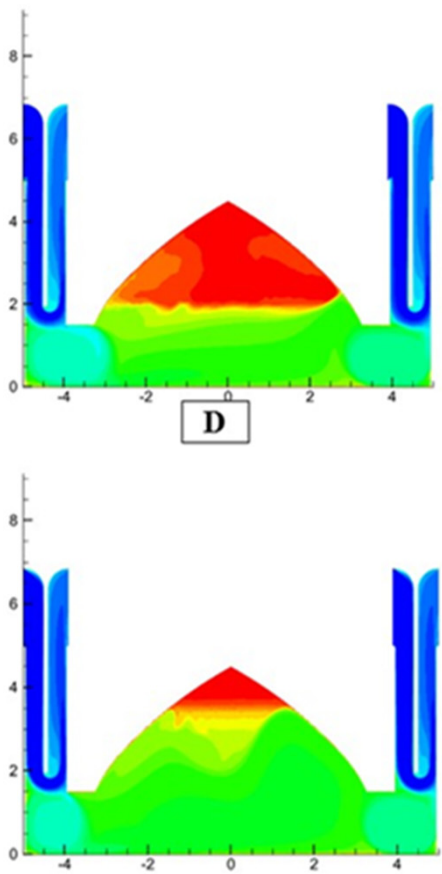

G

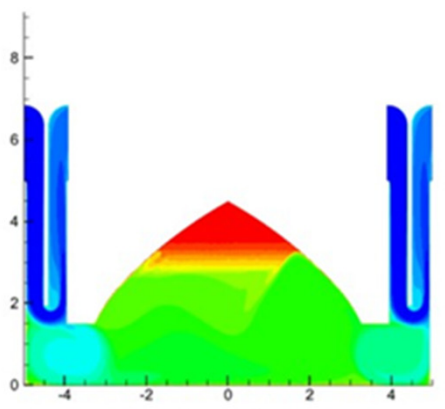

B
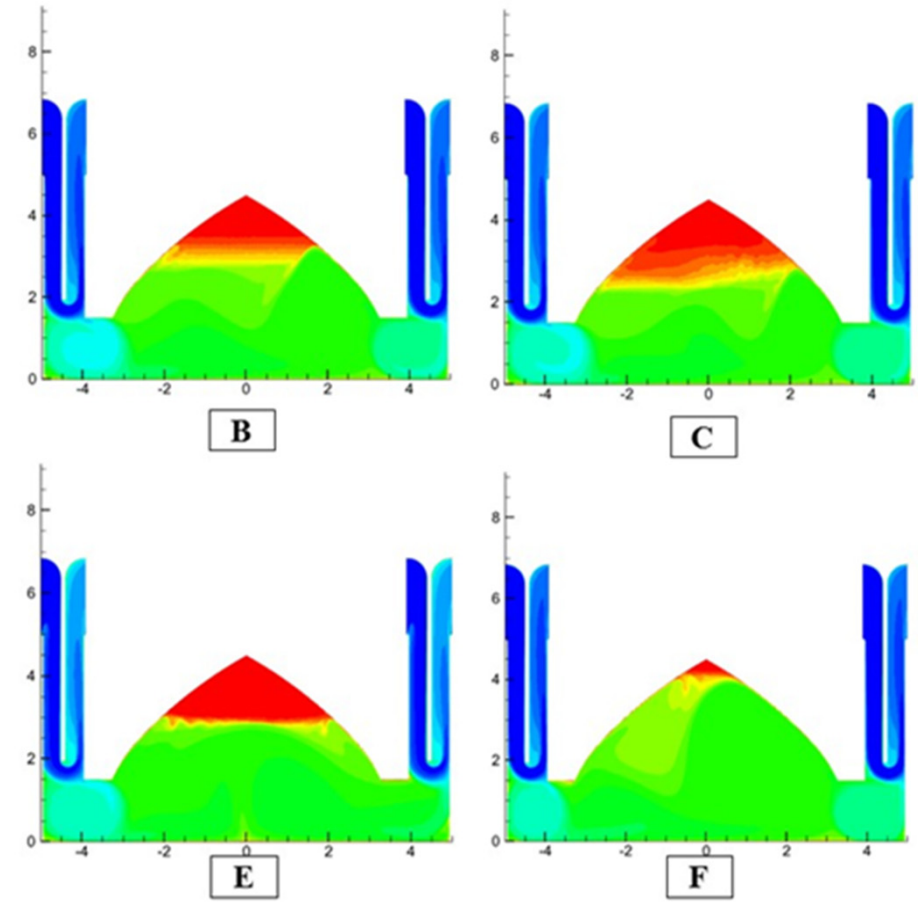

C
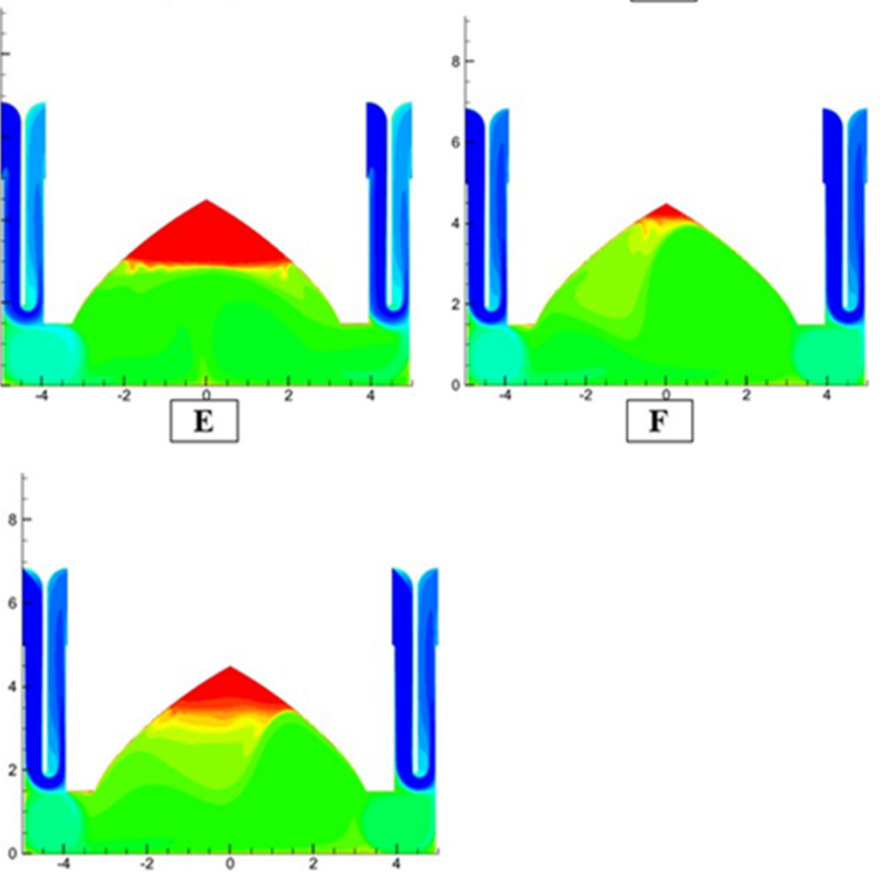

$\mathbf{H}$

Figure 8. Variations in total temperature $(\mathrm{K})$ range [source authors]. 
Table 4. Cases summary (temperature (K) and pressure (Pa)).

\begin{tabular}{ccccc}
\hline Case No. & Average Temperature & Inlet Pressure & Outlet Pressure & Pressure Losses \\
\hline Case A & 306.9182 & 235.1489 & 27.73132 & 207.41758 \\
\hline Case B & 307.1945 & 192.2397 & 20.75776 & 171.48194 \\
\hline Case C & 307.4432 & 130.9378 & 18.09442 & 112.84338 \\
\hline Case D & 307.986 & 67.3958 & 8.922777 & 58.473023 \\
\hline Case E & 307.4546 & 19.0712 & 2.255989 & 16.815211 \\
\hline Case F & 306.9133 & 227.7062 & 28.33965 & 199.36655 \\
\hline Case G & 307.1406 & 179.6935 & 19.7353 & 159.9582 \\
\hline Case H & 307.3899 & 116.219 & 16.35862 & 99.86038 \\
\hline
\end{tabular}

The second comparison factor is the airflow velocity inside the building. Airflow in a building reduces moisture damage and helps provide thermal comfort to the building's occupants. For airflow to occur naturally in this space, the towers provide a continuous flow path between the entrance and exhaust. The inlet air velocity is $2.4 \mathrm{~m} / \mathrm{s}$ and is constant in all cases. Figure 9 and Table 5 contain the value of velocity magnitude of airflow from the entrance to the exhaust of the airflow inside the building. Designs A, F, B, and G give the highest circulation velocity.

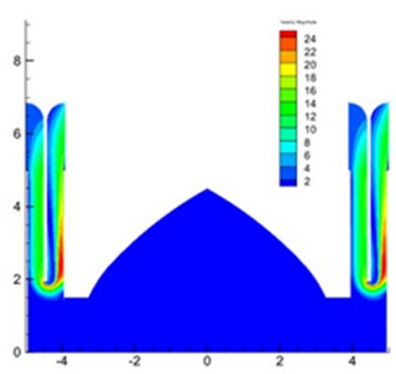

$\mathbf{A}$

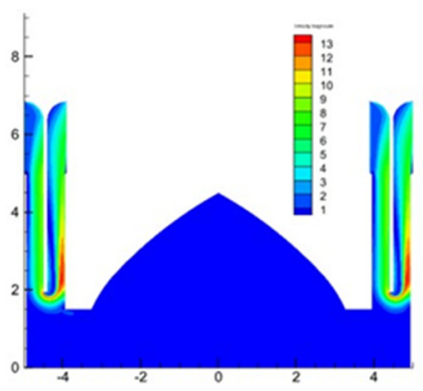

D

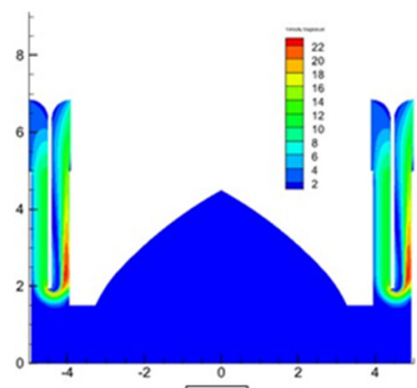

$\mathbf{G}$

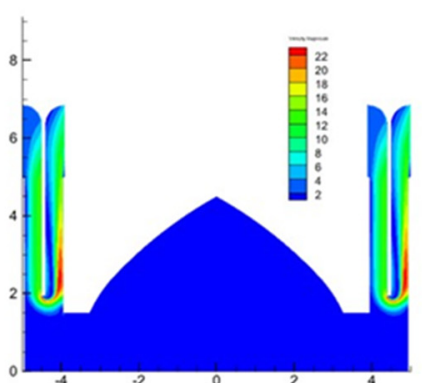

B

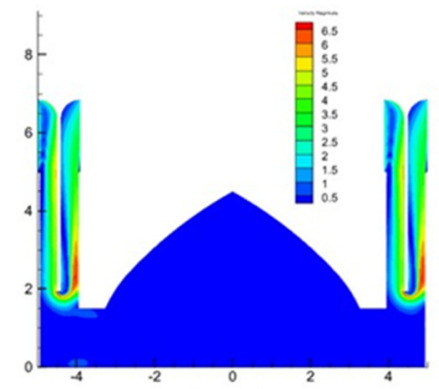

$\mathbf{E}$

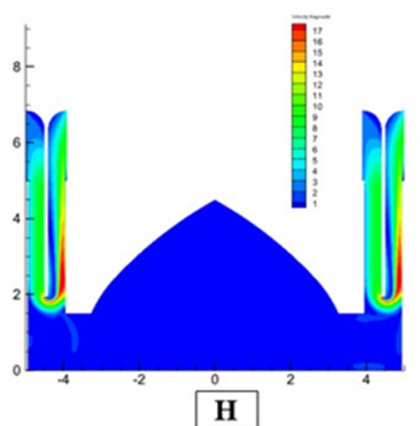

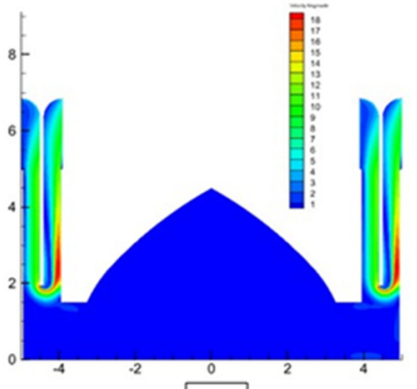

C

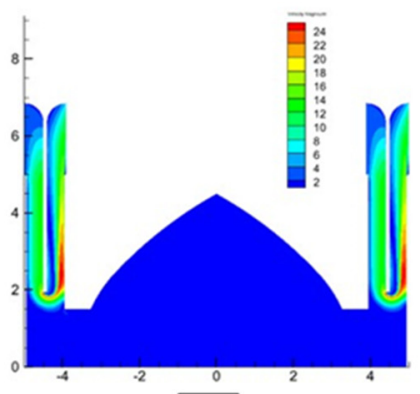

F

Figure 9. Velocity magnitude $(\mathrm{m} / \mathrm{s})$ range [source authors]. 
Table 5. Cases summary.

\begin{tabular}{ccc}
\hline Case No. & Wind Speed $(\mathbf{m} / \mathbf{s})$ & Velocity Magnitude Range $(\mathbf{m} / \mathbf{s})$ \\
\hline Case A & 2.4 & $2-24$ \\
\hline Case B & 2.4 & $2-22$ \\
\hline Case C & 2.4 & $1-18$ \\
\hline Case D & 2.4 & $1-13$ \\
\hline Case E & 2.4 & $0.5-6.5$ \\
\hline Case F & 2.4 & $2-24$ \\
\hline Case G & 2.4 & $2-22$ \\
\hline Case H & 2.4 & $1-17$ \\
\hline
\end{tabular}

Proper natural ventilation requires a combination of the best comparison factors (low total temperature and high air circulation). For this purpose, the angles of $+15^{\circ},-15^{\circ},+30^{\circ}$, and $-30^{\circ}$ have better ventilation, and increasing the distance from the horizon reduces this amount.

Finally, the performance of wind-catchers in reducing temperature and air circulation inside the water storage (Ab-Anbar) building with two two-sided wind-catchers in the city of Yazd in 8 cases based on different wind angles was studied. This study showed that one of the main goals of traditional architects in Yazd in the construction of wind-catchers in the prevailing wind direction (west and northwest) has been the maximum use of wind flow for cooling and natural ventilation of the building without using any mechanical means in hot seasons. Thus, $+15^{\circ},-15^{\circ},+30^{\circ}$, and $-30^{\circ}$ angles have the best ventilation, that is, west and northwest.

\section{Conclusions}

Iranian architects, fully aware of the principles of architecture and their native environment, have created the Ab-Anbar, which was an optimal way to use natural resources and energy. Ab-Anbars are a clear example of the importance of sustainability patterns in vernacular and traditional Iranian architecture. Unfortunately, today, these buildings, as with many other vernacular buildings, have lost their importance and function of the past with the advancement of technology and changes in people's lifestyles. Although AbAnbars are still used in some remote villages, the declining trend indicates their oblivion and complete destruction in the near future.

On the other hand, we have sought to gain the experiences of traditional architects of hot and dry climates and the patterns and elements used, especially the wind-catcher element, to increase the improvement of thermal conditions. Thus, different wind angles were analyzed and simulated to analyze the natural ventilation system of the wind-catcher in traditional Iranian architecture with CFD. Based on the results, the implementation of a natural ventilation strategy with wind-catchers in hot and dry climate residential buildings providing thermal comfort to residents is possible without the use of mechanical cooling.

Therefore, Ab-Anbars without the use of nonrenewable energy have played an important role in reducing energy consumption and improving convenience for users. The approach of reusing historical and local structures such as Ab-Anbars to store water and wind-catchers for the natural ventilation of buildings in hot and dry areas, while compensating for some deficiencies, increases the storage of available water resources and reduces the cost of water supply projects and artificial ventilation systems.

Author Contributions: Conceptualization, F.Y. and F.N.; Methodology, F.Y. and F.N.; Soft-ware, F.Y.; Validation, F.Y. and F.N.; Writing-original draft, F.Y.; Writing—review and editing, F.Y. and F.N. All authors have read and agreed to the published version of the manuscript.

Funding: This research received no external funding. 
Data Availability Statement: Data sharing not applicable.

Conflicts of Interest: The authors declare no conflict of interest.

\section{References}

1. Glassie, H. Architects, vernacular traditions, and society. Tradit. Dwell. Settl. Rev. 1990, 1, 9-21.

2. Kurbaş, B.; Neslinur, H. Learning from vernacular architecture: Ecological solutions in traditional Erzurum houses. Procedia-Soc. Behav. Sci. 2016, 216, 788-799. [CrossRef]

3. Keshtkaran, P. Harmonization between climate and architecture in vernacular heritage: A case study in Yazd, Iran. Procedia Eng. 2011, 21, 428-438. [CrossRef]

4. Shahbazi, M.; Abbasi, V. Study of the position of reservoirs in traditional Iranian architecture with respect to climate and sustainable development in Iran, a case study: Abanbar Shash Badgir Yazd. In Proceedings of the International Conference on Civil Engineering, Architecture, Urban Planning and Geography Science in Ancient and Contemporary Iran, Tehran, Iran, May 2016.

5. Esmaeili, S.; Litkouhi, S. Principles of sustainable architecture extant in heart of desert areas of Iran. Int. J. Archit. Eng. Urban. Plan. 2013, 23, 103-112.

6. Ghasemi, H.; Valipour, E.; Morad, D.; Tayyebisoudkolaei, S. Application of traditional architectural structure as sustainable approach to mitigation of shortage water supply in desert regions. Acad. J. Sci. 2013, 2, 125-132.

7. Mahan, A.; Khorramrouei, R.; Nasiri, A. Restoring the Qanats as a Traditional Water Transfer System: A Sustainable Approach. Int. J. Archit. Urban. Dev. 2019, 9, 35-42.

8. Saeidian, A. Ab-Anbar, sustainable traditional water supply system in hot arid regions, remarkable example of Iranian vernacular architecture. Elixir. Int. J. A 2013, 56, 13584-13590.

9. Nielsen, P.V. Fifty years of CFD for room air distribution. Build. Environ. 2015, 91, 78-90. [CrossRef]

10. Roache, P.J. Verification and Validation in Computational Science and Engineering; Hermosa: Albuquerque, NM, USA, 1998; Volume 895.

11. Versteeg, H.K.; Malalasekera, W. An Introduction to Computational Fluid Dynamics: The Finite Volume Method, 2nd ed.; Pearson Education Limited: Essex, UK, 2007.

12. Wilcox, D.C. Turbulence Modeling for CFD; DCW Industries: La Canada, CA, USA, 1998; Volume 2.

13. Ghadiri, M.H.; Mohamed, M.F.; Ibrahim, N.L.N. Cfd analysis of natural ventilation behaviour in four sided wind catcher. World Acad. Sci. Eng. Technol. 2012, 6, 704.

14. Awbi, H. Basic concepts for natural ventilation of buildings. In Proceedings of the CIBSE BSG Seminar: Natural and Mixed-Mode Ventilation Modelling, Reading, UK, 19 May 2010.

15. Montazeri, H.; Montazeri, F.; Azizian, R.; Mostafavi, S. Two-sided wind catcher performance evaluation using experimental, numerical and analytical modeling. Renew. Energy 2010, 35, 1424-1435. [CrossRef]

16. Montazeri, H. Experimental and numerical study on natural ventilation performance of various multi-opening wind catchers. Build. Environ. 2011, 46, 370-378. [CrossRef]

17. Reyes, V.A.; Moya, S.L.; Morales, J.M.; Sierra-Espinosa, F.Z. A study of air flow and heat transfer in building-wind tower passive cooling systems applied to arid and semi-arid regions of Mexico. Energy Build. 2013, 66, 211-221. [CrossRef]

18. Montazeri, H.; Montazeri, F. CFD simulation of cross-ventilation in buildings using rooftop wind-catchers: Impact of outlet openings. Renew. Energy 2018, 118, 502-520. [CrossRef]

19. Elmualim, A.A.; Awbi, H.B. Wind tunnel and CFD investigation of the performance of "Windcatcher" ventilation systems. Int. J. Vent. 2002, 1, 53-64. [CrossRef]

20. Hughes, B.R.; Ghani, S.A. Investigation of a windvent passive ventilation device against current fresh air supply recommendations. Energy Build. 2008, 40, 1651-1659. [CrossRef]

21. Jones, B.M.; Kirby, R. Quantifying the performance of a top-down natural ventilation Windcatcher ${ }^{\mathrm{TM}}$. Build. Environ. 2009, 44, 1925-1934. [CrossRef]

22. Salehi, A.; Fayaz, R.; Bozorgi, M.; Asadi, S.; Costanzo, V.; Imani, N.; Nocera, F. Investigation of thermal comfort efficacy of solar chimneys under different climates and operation time periods. Energy Build. 2019, 205, 109528. [CrossRef]

23. Le Strange, G. Historical Geography of the Lands of the Eastern Caliphate; Erfan, M., Translator; Scientific and Cultural Publications: Tehran, Iran, 2004. (In Persian)

24. Memarian, G. Introducing a corner of unknown Iranian architecture: Ab-Anbar building. Architect. Urban Plan. $2009,1,125-141$. (In Persian)

25. Beazley, E. Some vernacular buildings of the Iranian plateau. Iran 1977, 15, 89-102. [CrossRef]

26. Daiiallah, M.; Shoae, A.A. Principles of sustainable development in architecture and urbanism of Iran's hot and dry Climate in the past. Danesh Nama (Tech.-Prof. Mon. J.) 2014, 21, 15-21.

27. Reza, A.; Kors, G.R.; Shoushtari, M.A.; Entezami, A.A. Water and Technology of Irrigation in Ancient Iran; Ministry of Water and Electricity: Iran, Tehran, 1971.

28. Pearlmutter, D.; Erell, E.; Etzion, Y. A multi-stage down-draft evaporative cool tower for semi-enclosed spaces: Experiments with a water spraying system. Sol. Energy 2008, 82, 430-440. [CrossRef] 
29. Fryer, J. A New Account of the East Indies and Persia Being Nine years Travels, 1672-1681; Crooke, W., Ed.; Cultural Research Association: Tehran, Iran, 1963; p. 149.

30. Ali, A.H.H. Passive Cooling of Water at Night in Uninsulated Open Tank in Hot Arid Areas. Energy Convers. Manag. 2007, 48, 93-100. [CrossRef]

31. Siroux, M. The Caravanserais of Iran and the Small Buildings in between the Roads; Behnam, I., Ed.; National Iranian Organization of Historic Preservation: Tehran, Iran, 1970.

32. Sotoudeh, M. Iran. and Islam Encyclopedia; Translation and Publishing Institute: Tehran, Iran, 1977.

33. Masoumi, H.E. A New Approach to the Iranian Urban Planning, Using Neo-Traditional Development. Ph.D. Thesis, Technical University of Dortmund, Dortmund, Germany, December 2011.

34. Varjavand, P.; Kiani, M.Y. Ab Anbarha' in The Architecture of Islamic Iran; Samt Publications: Tehran, Iran, 2000; pp. 154-165. (In Persian)

35. Ghobadian, V. Climatic Study of Traditional Iranian Buildings; Publication of Tehran University: Tehran, Iran, 2005. (In Persian)

36. Valipour, E.; Oshrieh, R. Survey of Traditional Wind Catchers of the Middle East. In Proceedings of the International Conference on Sustainable Design, Engineering, and Construction 2012, Fort Worth, TX, USA, 7-9 November 2012; American Society of Civil Engineers: Reston, VA, USA, 2013; pp. 912-920.

37. Khan, N.; Su, Y.; Riffat, S.B. A review on wind driven ventilation techniques. Energy Build. 2008, 40, 1586-1604. [CrossRef]

38. Sayigh, A. Sustainability, Energy and Architecture: Case Studies in Realizing Green Buildings, 1st ed.; Academic Press: Cambridge, MA, USA, 25 September 2013.

39. Saeli, M.; Saeli, E. Analytical studies of the Sirocco room of Villa Naselli-Ambleri: A XVI century passive cooling structure in Palermo (Sicily). J. Cult. Herit. 2015, 16, 344-351. [CrossRef]

40. Fanood, M.R. The role of four key structures in the creation and survival of cultural landscapes in the desert environment of Iran. J. Archit. Conserv. 2014, 20, 184-196. [CrossRef]

41. Patel, D.; Rajan, S.T.; Patel, D.D.; Rajan, S.T. Design of a passive and wind speed responsive wind catcher for energy efficient buildings. IJIRST_Int. J. Innov. Res. Sci. Technol. 2015, 1, 125-128.

42. Montazeri, H.; Azizian, R. Experimental study on natural ventilation performance of a two-sided wind catcher. Proc. Inst. Mech. Eng. Part. A J. Power Energy 2009, 223, 387-400. [CrossRef]

43. Liu, L.; Mak, C.M. The assessment of the performance of a wind catcher system using computational fluid dynamics. Build. Environ. 2007, 42, 1135-1141. [CrossRef]

44. Zarmehr, A.; Kider, J.T., Jr. Modeling and Simulation of Parametric Wind-Catcher Designs for Natural Ventilation in Sus-tainable Building Skin Architecture. In Proceedings of the 13th Conference on Advanced Building Skins, Bern, Switzerland, 1-2 October 2018; pp. 937-945.

45. Fernandez-Antolin, M.-M.; Río, J.M.; Costanzo, V.; Nocera, F.; Gonzalez-Lezcano, R.-A. Passive design strategies for residential buildings in different Spanish climate zones. Sustainability 2019, 11, 4816. [CrossRef]

46. Nocera, F.; Caponetto, R.; Giuffrida, G.; Detommaso, M. Energetic retrofit strategies for traditional Sicilian wine cellars: A case study. Energies 2020, 13, 323. [CrossRef]

47. Seyam, S. Types of HVAC Systems. IntechOpen 2018, 4, 49-66. Available online: https://books.google.com/books?hl=en\& $\mathrm{lr}=\& \mathrm{id}=\mathrm{aCRDwAAQBAJ} \& \mathrm{oi}=$ fnd\&pg=PA49\&dq=Types+of+HVAC+systems\&ots=s9A9L6LgJr\&sig=WGZMNJrfwZwXU9 ZuhZo_0vVrYc\#v=onepage\&q=Types\%20of\%20HVAC\%20systems\&f=false (accessed on 2 September 2021). 